\title{
Epicardial Fat Thickness in Children with Subclinical Hypothyroidism and Its Relationship to Subclinical Atherosclerosis: A Pilot Study
}

\author{
Hekma Saad Farghalya Kotb Abbass Metwalley ${ }^{a}$ Duaa Mohamed Raafat ${ }^{a}$ \\ Magdy Algowhary ${ }^{b}$ Ghada Mohamed Said ${ }^{c}$ \\ ${ }^{a}$ Department of Pediatrics, Faculty of Medicine, Assiut University, Assiut, Egypt; ${ }^{b}$ Department of Cardiology, \\ Faculty of Medicine, Assiut University, Assiut, Egypt; ${ }^{C}$ Department of Clinical Pathology, Faculty of Medicine, Assiut \\ University, Assiut, Egypt
}

\section{Keywords}

Subclinical hypothyroidism · Echocardiography $\cdot$ Epicardial fat thickness · Carotid intima media thickness

\begin{abstract}
Background/Aims: Thyroid hormones (TSH) play a key role in the working of the cardiovascular system, with direct effects on cardiac function, vascular system, and atherosclerotic factors. Epicardial adipose tissue, the visceral fat of the heart, has emerged as a new cardiometabolic risk marker because of its close anatomical proximity to the myocardium and coronary artery. This study aimed to evaluate epicardial fat thickness (EFT) in children with subclinical hypothyroidism (SH) and its relation to early atherosclerotic changes. Methods: The study included 32 children with SH due to autoimmune thyroiditis and 32 healthy children matched for age and gender as control group. Patients and controls underwent anthropometric evaluation and measurement of fasting lipids, glucose, insulin, homeostasis model assessment for insulin resistance and high-sensitivity C-reactive protein (hs-CRP). TSH, free thyroxine (FT4 and FT3) and antithyroid autoantibodies (antithyroid peroxidase and thyroglobulin antibodies) were also measured. Conventional echocardiography was used to assess EFT. Noninvasive ultrasound
\end{abstract}

was used to measure carotid intima-media thickness and brachial artery flow-mediated dilation (FMD) responses. $\boldsymbol{R} \boldsymbol{e}$ sults: Compared to controls, patients had higher atherogenic index (Al) and hs-CRP ( $p=0.001$ for each). Conventional echocardiography revealed that patients with $\mathrm{SH}$ had higher EFT $(p=01)$ and significantly lower FMD response compared with the control $(p=0.001)$. In multivariate analysis, EFT values were significantly correlated with TSH (OR 1.2; $95 \% \mathrm{CI}$ $1.04-1.34 ; p=0.01)$, hs-CRP (OR 1.1; 95\% Cl 1.09-1.14; $p=$ 0.001 , Al (OR 1.6; 95\% Cl 1.17-2.03; $p=0.001)$, and FMD response (OR 2.4; 95\% Cl 1.14-2.53; $p=0.01)$. Conclusions: Our study demonstrated that EFT is higher in children with $\mathrm{SH}$ compared with controls and associated with FMD responses. Measurement of EFT by echocardiography in children with $\mathrm{SH}$ may help to identify those at high risk of developing subclinical atherosclerosis.

๑) 2019 S. Karger AG, Basel

\section{Introduction}

Subclinical hypothyroidism $(\mathrm{SH})$ is a biochemical condition where thyrotropin hormones (TSH) serum levels are above the upper limit of the reference range for the assay, whereas free thyroxine (FT4) values are within the

\section{KARGER}

(c) 2019 S. Karger AG, Basel

E-Mail karger@karger.com

www.karger.com/hrp
Dr. Hekma Saad Farghaly

Department of Pediatrics

Faculty of Medicine, Assiut University

Assiut 71111 (Egypt)

E-Mail hekmafarghly73@gmail.com 
reference interval of the assay [1]. Few data are available from epidemiological studies conducted among children and adolescents. Data from NHANES III indicated a prevalence of $1.7 \%$ for $\mathrm{SH}$ among 1,327 adolescents aged 13-16 years [2]. In childhood and adolescence, $\mathrm{SH}$ is caused by the same thyroid disorders that cause overt thyroid failure, in particular Hashimoto's thyroiditis (HT); in many cases, however, no defined etiology can be detected (idiopathic $\mathrm{SH}$ ) [3]. Individuals with $\mathrm{SH}$ are either asymptomatic or present with milder symptoms than those with overt hypothyroidism [4]. The natural history of SH may significantly differ in children compared to adult [5]. Whereas in adults, it is often observed as a progressive shift from euthyroidism toward $\mathrm{SH}$ or frank hypothyroidism [6], and in childhood and adolescence, the natural long-term evolution of thyroid tests may be quite variable. In fact, in the 4-year follow-up study by Radetti et al. [7], the majority of initially euthyroid patients remained euthyroid. In contrast, Aversa et al. [8], only $57.1 \%$ of initially euthyroid children remained euthyroid even 5 years after HT diagnosis. The remaining $42.9 \%$ deteriorated their thyroid status over time, thus developing a $\mathrm{SH}$ in $30.6 \%$ of cases and an overt biochemical hypothyroidism in $12.3 \%$ [8]. Since cardiovascular system is rich in TSH receptors and is one of the major sites of action for TSH, it is relatively sensitive to changes in the levels of TSH [9]. Adult studies have shown that $\mathrm{SH}$ is associated with cardiovascular dysfunction $[10,11]$. However, there is still controversy about the association of cardiovascular dysfunction in children with $\mathrm{SH}[12,13]$.

Epicardial fat thickness (EFT) is a layer of adipose tissue surrounding the heart and coronary vessels that can be measured by ultrasound, a simple, noninvasive procedure [14] EFT is a reliable and sensitive marker of cardiovascular risk and has become an emerging target for therapeutic and medical interventions [15]. In recent years, there are few studies that evaluated EFT in adults with SH $[16,17]$. To our knowledge, there is no published data about EFT in children with SH. This study aimed to evaluate EFT in children with $\mathrm{SH}$ and its association with early atherosclerotic changes.

\section{Patients and Methods}

This cross-sectional case - control study included 32 children (22 females and 10 males) (mean age $=13.6 \pm 2.5$ years) with a confirmed diagnosis of $\mathrm{SH}$ as a consequence of autoimmune thyroiditis (AIT). Diagnosis of AIT was done by detection of elevated serum level of antithyroid peroxidase antibodies (TPOAb) and/or antithyroglobulin antibodies ( $\mathrm{TgAb}$ ) and the typical finding of hy- poechogenicity of the thyroid gland on high-resolution ultrasound scans [18]. All SH patients had TSH serum levels ranging between 4 and $10 \mu \mathrm{IU} / \mathrm{mL}$, with FT4 in the normal range [19], which was confirmed in a second measurement, 8 weeks apart from the first one. Patients with serum TSH $>10 \mu \mathrm{IU} / \mathrm{mL}$ were excluded to guarantee a homogeneous group of patients with minimal thyroid dysfunction in which there is still doubts about the benefits of levothyroxine treatment [20]. Patients were recruited from Pediatric Endocrinology Outpatient Clinic of Assiut Children's University Hospital, Assiut Egypt. Overweight, obese, and syndromic children were excluded from study in addition to children with other autoimmune diseases, malignancies, family history of increased cardiovascular risk, and those who were treated with medications affecting thyroid function were excluded also from the study. Thirty-two euthyroid healthy children ( 7 males and 27 females) matched for age, gender, pubertal status, and socioeconomic status as control. The inclusion criteria for the control group were demonstration of normal serum TSH and FT4, negative antithyroid antibodies, and no past history of thyroid disease. Control subjects were recruited from the General Pediatric Outpatient Clinic of Assiut Children's University Hospital, Assiut Egypt. Controls were attending the outpatient clinic either because of minor illness or accompanying their sick siblings. The study protocol was performed in accordance with the standards laid down in the Declaration of Helsinki and its later amendments and approved by the Ethics Committee of Faculty of Medicine, Assiut University, Assiut, Egypt. Informed written consents were obtained from the parents of all participants before enrollment in the study.

\section{Methods}

All participants were subjected to full medical histories and examinations. Height and weight were measured using a wallmounted stadiometer and a calibrated weight scale, and the child was wearing the underwear only. BMI was calculated using the following formula: $\mathrm{BMI}=$ weight $(\mathrm{kg}) /$ height $(\mathrm{m})^{2}$. BMI was expressed as SD scores using the Egyptian Growth Reference Data [21]. Puberty was classified according to Tanner staging [22]. Blood pressure was measured in a controlled environment after $5 \mathrm{~min}$ of rest in the seated position with the right arm supported at heart level. If the blood pressure was greater than the 90th percentile for age and sex, it was repeated twice on the same visit to confirm the reading [23]. Subjects were considered hypertensive if the average systolic and/or diastolic blood pressure was $\geq 95$ th percentile for sex, age, and height on 3 or more occasions [24].

\section{Laboratory Investigations}

Blood samples were drawn after an overnight fast for at least $12 \mathrm{~h}$ at 8:00-10:00 a.m. for assessment of the serum levels of total cholesterol (TC), triglycerides, high-density lipoprotein cholesterol (HDL-c), low-density lipoprotein cholesterol, glucose, and insulin. Levels of TC, triglycerides, HDL-c, and low-density lipoprotein cholesterol were measured by the enzymatic colorimetric method using the autoanalyzer Hitachi 911 (Boehringer Mannheim, Indianapolis, IN, USA). The atherogenic index (AI) was calculated as the ratio of TC to HDL-c [25]. Insulin levels were measured using electrochemiluminescence immunoassay "ECLIA" (Roche Elecsys 1010/2010 and Modular analytics E170, Roche Diagnostics GmbH, Mannheim, USA). IR was calculated using the homeostasis model assessment (HOMA-IR) equation formula as follows: HOMA-IR = fasting insulin $(\mu \mathrm{U} / \mathrm{mL})$ multiplied by fasting glucose $(\mathrm{mmol} / \mathrm{L})$ di- 
Table 1. Clinical, biochemical, hormonal, and immunological parameters in children with subclinical hypothyroidism compared with controls

\begin{tabular}{|c|c|c|c|}
\hline & $\begin{array}{l}\text { SH cases }(n=32) \\
\text { mean } \pm \text { SD }\end{array}$ & $\begin{array}{l}\text { Controls }(n=32) \\
\text { mean } \pm \text { SD }\end{array}$ & $p$ value \\
\hline Age, years & $13.6 \pm 2.4$ & $13.2 \pm 2.1$ & ns \\
\hline Height SDS & $-0.64 \pm 1.36$ & $-0.45 \pm 1.26$ & ns \\
\hline BMI SDS & $0.23 \pm 1.06$ & $0.21 \pm 1.25$ & ns \\
\hline Pubertal cases, $n(\%)$ & $22 / 32(68.7)$ & $21 / 32(65.6)$ & ns \\
\hline $\mathrm{SBP}, \mathrm{mm} \mathrm{Hg}$ & $105.0 \pm 14.9$ & $104.4 \pm 12.2$ & ns \\
\hline $\mathrm{DBP}, \mathrm{mm} \mathrm{Hg}$ & $67.1 \pm 9.7$ & $65.6 \pm 8.5$ & ns \\
\hline $\mathrm{TC}, \mathrm{mg} / \mathrm{dL}$ & $159.76 \pm 22.34$ & $160.44 \pm 21.23$ & ns \\
\hline $\mathrm{TG}, \mathrm{mg} / \mathrm{dL}$ & $74.57 \pm 39.55$ & $65.36 \pm 25.21$ & ns \\
\hline LDL-c, mg/dL & $94.36 \pm 26.23$ & $87.15 \pm 18.45$ & ns \\
\hline $\mathrm{HDL}-\mathrm{c}, \mathrm{mg} / \mathrm{dL}$ & $44.46 \pm 11.34$ & $61.07 \pm 14.86$ & 0.01 \\
\hline Atherogenic index & $4.32 \pm 0.90$ & $2.48 \pm 0.68$ & 0.01 \\
\hline Fasting blood glucose, mg/dL & $74.42 \pm 4.52$ & $83.30 \pm 8.16$ & ns \\
\hline Fasting insulin, $\mu \mathrm{U} / \mathrm{mL}$ & $7.01 \pm 4.25$ & $5.67 \pm 3.60$ & ns \\
\hline HOMA-IR & $1.38 \pm 0.80$ & $1.09 \pm 0.60$ & ns \\
\hline hsCRP, mg/L & $189 \pm 13.5$ & $76.9 \pm 11.8$ & 0.01 \\
\hline TSH*, mU/L & $6.3(4.9-9.6)$ & $1.9(1.15-2.8)$ & 0.01 \\
\hline $\mathrm{TSH}^{*}, \mathrm{mU} / \mathrm{L} \mathrm{IQR}$ & $2.3-5.9$ & $0.87-1.4$ & \\
\hline $\mathrm{FT} 4, \mathrm{pmol} / \mathrm{L}$ & $17.9 \pm 3.12 .2$ & $18.9 \pm 2.16 .2$ & ns \\
\hline $\mathrm{FT} 3, \mathrm{pmol} / \mathrm{L}$ & $4.4 \pm 1.1$ & $4.6 \pm 1.2$ & ns \\
\hline TPOAbs, IU/mL & $147.7 \pm 21.9$ & $63.7 \pm 4.5$ & 0.001 \\
\hline TgAbs, IU/mL & $123.4 \pm 16.8$ & $14.1 \pm 4.6$ & 0.001 \\
\hline
\end{tabular}

* Results of TSH are expressed as median, range, and the IQR. ns, nonsignificant; BMI-SDS, body mass index slandered deviation score; TSH, thyroid-stimulating hormone; FT4, free thyroxine; FT3, free triiodothyronine; TPOAbs, thyroid peroxidase antibodies; TRAbs, thyrotropin-stimulating hormone receptor antibodies; TgAbs, thyroglobulin antibodies; LDL-c, low-density lipoprotein cholesterol; HDL-c, high-density lipoprotein cholesterol; HOMA-IR, the homeostasis model assessment of insulin resistance; hs-CRP, high-sensitivity C-reactive protein; IQR, interquartile range; TC, total cholesterol; TG, triglycerides.

vided by 22.5. Patients were considered to have IR if HOMA-IR $\geq 2.6$ [26]. Serum levels of TSH, FT4, and FT3 were determined by ultrasensitive immunometric assays (Immulite ${ }^{\mathrm{TM}} 2000$ Third Generation, Diagnostic Products Corporation, Los Angeles, CA, USA). The reference ranges for TSH were as follows: $\mathrm{TSH}=0.4-4.0 \mathrm{mU} / \mathrm{L}$, FT4: $=10.0-26.0 \mathrm{pmol} / \mathrm{L}$, and FT3 $=3.5-5.5 \mathrm{pmol} / \mathrm{L}$. The coefficients of variations for TSH were as follows: TSH $=5.0$ and $5.1 \%$ at concentrations of 4.0 and $10.0 \mathrm{mU} / \mathrm{L}$, respectively; FT4 $=6.5 \%$ at concentrations of $10.0 \mathrm{pmol} / \mathrm{L}$; and $\mathrm{FT} 3=8.9 \%$ at concentrations of $3.5 \mathrm{pmol} / \mathrm{L}$. Serum TPOAb and TgAb were measured by rapid enzyme-linked immunosorbent assay (Genesis Diagnostics, Littleport, UK). TgAb and TPOAb concentrations $>100$ and $75 \mathrm{IU} / \mathrm{mL}$, respectively, were considered positive and at least one positive antibody conferred the diagnosis of AIT.

\section{EFT Measurement}

All participants underwent echocardiographic examination using Philips Envisor Ultrasound System with an S4-2 Broadband Sector (Philips Medical Systems, Inc.). The two-dimensional echocardiogram, using a standardized procedure, was performed with the patient in the left lateral decubitus position. EFT thickness was measured by an experienced pediatric echocardiologist, who was blinded to the subjects' clinical and demographic data, using the procedure validated by Iacobellis et al. [27]. EFT was identified as the echolucent region between the external wall of the myocardium and the visceral layer of the pericardium. This thickness was measured perpendicularly on the free wall of the right ventricle at the end of systole over 3 cardiac cycles, using a parasternal long and a parasternal short axis. The average value of the 3 cardiac cycles from each echocardiographic view was used for the statistical analysis.

Flow-Mediated Dilation and Brachial Artery Distensibility

The brachial artery was scanned above the antecubital fossa, and its diameter was measured from B-mode ultrasound images with the patient at rest (baseline brachial artery diameter). Reactive hyperemia was then induced by inflation of a pneumatic tourniquet placed around the forearm to a pressure of $250 \mathrm{~mm} \mathrm{Hg}$ for 4.5 min, followed by release. A second scan of vessel diameter was performed at a fixed distance manually using ultrasonic calipers (maximal brachial artery diameter). Longitudinal images were scanned and captured (in millimeters) at end diastole incident with the R-wave on a continuously recorded ECG. The flow-mediated dilation (FMD) was calculated and expressed as a percent- 
Table 2. The EFT, CA-IMT, and peak FMD \% values in the studied groups

\begin{tabular}{lccl}
\hline & $\begin{array}{l}\text { SH cases } \\
(n=32)\end{array}$ & $\begin{array}{l}\text { Controls } \\
(n=32)\end{array}$ & $p$ value \\
\hline EFT, mm & $7.7 \pm 1.4$ & $4.7 \pm 1.2$ & 0.01 \\
CA-IMT, mm & $0.44 \pm 0.08$ & $0.44 \pm 0.06$ & ns \\
Peak FMD, \% & $4.60 \pm 2.13$ & $9.31 \pm 2.29$ & 0.001 \\
\hline
\end{tabular}

Data are expressed as mean \pm SD. EFT, epicardial fat thickness; CA-IMT, carotid intima-media thickness; FMD, flow-mediated dilation; ns, nonsignificant.

Table 3. The correlation between EFT and anthropometric, laboratory and echocardiographic data in children with $\mathrm{SH}$

\begin{tabular}{lcl}
\hline Parameter & $r$ value & $p$ value \\
\hline Age, years & 0.384 & 0.011 \\
BMI SDS & 0.334 & 0.01 \\
SBP, mm Hg & 0.234 & ns \\
DBP, mm Hg & 0.181 & ns \\
HOMA-IR & 0.562 & 0.001 \\
hs-CRP, mg/L & 0.686 & 0.001 \\
TC, mg/dL & 0.315 & 0.01 \\
TG, mg/dL & 0.146 & ns \\
LDL-c, mg/dL & 0.314 & 0.05 \\
HDL-c, mg/dL & 0.658 & 0.001 \\
AI & 0.554 & 0.001 \\
TSH, $\mu$ lU/ML & 0.388 & 0.01 \\
FT4, pmol/L & -0.188 & ns \\
FT3, pmol/L & -0.146 & ns \\
CA-IMT, mm & 0.405 & 0.01 \\
Peak FMD, \% & -0.543 & 0.001 \\
\hline
\end{tabular}

The AI was calculated as the ratio of TC to HDL-c. SDS-BMI, standard deviation scores of body mass index; SBP, systolic blood pressure; DBP, diastolic blood pressure; HOMA-IR, the homeostasis model assessment of insulin resistance; HDL-c, high-density lipoprotein cholesterol; EFT, epicardial fat thickness; CA-IMT, carotid-intima media thickness; $\mathrm{SH}$, subclinical hypothyroidism; TSH, thyroid-stimulating hormone; FT4, free thyroxine; FT3, free triiodothyronine hs-CRP, high-sensitivity C-reactive protein; $\mathrm{AI}$, atherogenic index; FMD, flow-mediated dilation; TC, total cholesterol; TG, triglycerides; ns, nonsignificant.

age. FMD was calculated according to the formula [28]: FMD $=\%$ mean diameter of the hyperemic flow-baseline diameter/baseline.

\section{Measurement of Carotid IMT}

Measurement: All participants underwent an ultrasound scan to measure carotid intima-media thickness (CA-IMT). The studies were performed in the morning between 7:30 and 9:30 am after the children had fasted overnight. All ultrasound scans were performed by an experienced vascular operator who was unaware of the subject's clinical details. Examination of CA-IMT was manually performed using a color duplex flow imaging system (Acuson 128 XP; Acuson Corporation, Mountain View, CA, USA). The examinations were performed, while the patients were in a supine position, with their necks slightly extended and their heads turned 450 away from the examination side. From both sides of the head, 3 images were obtained from the distal common carotid artery, 1-2 $\mathrm{cm}$ proximal to the carotid bulb at end diastole. These images were then stored for later offline analyses. All studies were done according to a predetermined, standardized scanning protocol for the right and left carotid arteries [29]. All measurements were performed in all participants by the same pediatric cardiologist who was blinded to the clinical status of the study participants. Reliability of measurements of EFT, CA-IMT, and FMD were assessed by intraobserver correlation coefficient in all subjects.

\section{Statistical Analysis}

All statistical analyses were carried out using Statistical Package for the Social Sciences version 18.0 (Statistical Package for the Social Sciences Inc., Chicago, IL, USA). Data are expressed as mean \pm $\mathrm{SD}$ or median, range, and interquartile range. A comparison of parametric values between the 2 groups was made using a twotailed Student $t$ test, and for nonparametric values, Mann-Whitney $\mathrm{U}$ test was used. Categorical variables were compared using the chisquare test or Fisher's exact test. Correlations between EFT and demographic, clinical, and laboratory variables were assessed using Pearson test. Multiple logistic regression analysis was used to determine the factors that were significantly associated with high EFT. The ORs, 95\% CIs, and significances were calculated. For all tests, values of $p<0.05$ were considered statistically significant.

\section{Results}

The demographic, clinical, and laboratory characteristics of the studied groups (Table 1) show no significant differences were observed in height SD score and BMI SD between patients and controls. HDL-C levels were significantly lower, whereas AI was significantly higher in $\mathrm{SH}$ subjects compared with controls As expected, TSH levels were significantly higher in $\mathrm{SH}$ subjects comparable to controls, while FT4 and FT3 concentrations were similar in SH children and controls. The prevalence rates of pubertal children at HT did not significantly differ between the 2 groups. The EFT, CA-IMT, and peak FMD characteristics of the studied groups (Table 2) show no significant differences in CA-IMT between patients and control subjects. However, compared to control subjects, patients had significantly higher EFT (0.01) and significantly lower peak FMD response (0.001). The correlation between EFT with different demographic anthropometric, laboratory, and echocardiographic data in children with SH (Table 3) show a statistically significant positive correlation between EFT and age, TSH, high-sensitivity C-reactive protein (hs-CRP), AI, and significant negative correlation 
with peak FMD response The Multivariate correlation coefficients between EFT and various confounding variables in children with SH (Table 4) show EFT values were significantly correlated with TSH (OR 1.2; 95\% CI 1.04-1.34; $p=0.01$ ), hs-CRP (OR 1.1; 95\% CI 1.09-1.14; $p=0.001$, AI (OR 1.6; 95\% CI 1.17-2.03; $p=0.001$ ), and FMD response (OR 2.4; 95\% CI 1.14-2.53; $p=0.01$ ).

\section{Discussion}

The growing need to prevent cardiovascular diseases during adulthood increases the importance of understanding cardiac affection in children with $\mathrm{SH}$ [30]. This study demonstrates that (a) EFT was higher in children with SH than in the healthy controls; (b) children with $\mathrm{SH}$ may have subclinical atherosclerosis; (c) EFT is correlated with FMD responses, AI, and hs-CRP and (d) the study suggested that EFT may be used as an additional marker of endothelial dysfunction in children with $\mathrm{SH}$.

In the current study, EFT was significantly higher in children with SH compared with control children $(p=0.01)$. Furthermore, we demonstrated a significant positive correlation between EFT and serum TSH levels that reminded significant after regression analysis suggesting a direct causal relationship between SH and EFT. On the other hand, EFT failed to be associated with cholesterol and BMI by regression analysis. The previous studies reported higher EFT in adults with SH $[31,32]$. Functional TSH receptors are present on adipocytes during differentiation and in fully differentiated adipocytes [33]. As TSH stimulates adipogenesis from an early stage, it is possible that higher levels of TSH are associated with a preferential increase in EFT, thus contributing to an increased cardiovascular risk [34, 35].

In the present study, AI was significantly higher, and HDL-C levels were significantly lower in children with SH compared with control; moreover, AI correlated positively with EFT that remained significant after regression analysis. HDL-C and AI are surrogate markers of atherosclerosis and cardiometabolic risk even in childhood [31]. Disturbances in TSH concentrations may promote hyperlipidemia that may accumulate in the EF tissue in the same way as in the coronary artery vessels [15].

In this study, children with $\mathrm{SH}$ showed significantly lower FMD and nonsignificant difference in CA-IMT compared with the control group. On the other hand, Cerbone et al. [36] failed to demonstrate any significant alterations in FMD and CA-IMT among 39 children with mild $\mathrm{SH}$, while Isik-Balci et al. [37] found that CA-IMT in children with $\mathrm{SH}$ was significantly higher than in the control
Table 4. Multivariate correlation coefficients between EFT and various confounding variables in children with $\mathrm{SH}$

\begin{tabular}{lll}
\hline Confounding variables & OR & $95 \% \mathrm{CI}$ \\
\hline Age (years) & 0.65 & $0.71-1.04$ \\
BMI SDS & 0.94 & $0.69-1.27$ \\
SBP $(\mathrm{mm} \mathrm{Hg})$ & 0.82 & $0.87-1.24$ \\
DBP $(\mathrm{mm} \mathrm{Hg})$ & 0.92 & $0.95-1.4$ \\
HOMA-IR & 1.0 & $0.92-1.09$ \\
hs-CRP & $1.1^{* *}$ & $1.09-1.14$ \\
TC $(\mathrm{mg} / \mathrm{dL})$ & 0.89 & $1.05-1.12$ \\
TG $(\mathrm{mg} / \mathrm{dL})$ & 0.99 & $0.97-1.01$ \\
LDL-c $(\mathrm{mg} / \mathrm{dL})$ & 0.76 & $0.87-1.21$ \\
HDL-c $(\mathrm{mg} / \mathrm{dL})$ & 0.96 & $0.99-1.54$ \\
AI & $1.6^{* * *}$ & $1.17-2.03$ \\
TSH $(\mu \mathrm{IU} / \mathrm{mL})$ & $1.2^{* *}$ & $1.04-1.34$ \\
FT4 $(\mathrm{pmol} / \mathrm{L})$ & 0.97 & $0.76-1.32$ \\
FT3 $(\mathrm{pmol} / \mathrm{L})$ & 0.75 & $0.82-1.11$ \\
CA-IMT $(\mathrm{mm})$ & 0.97 & $0.93-1.4$ \\
Peak FMD $(\%)$ & $2.4^{* *}$ & $1.14-2.53$ \\
\hline
\end{tabular}

Significance, ${ }^{* *} 0.01,{ }^{* * *} 0.001$. EFT, epicardial fat thickness; $\mathrm{SH}$, subclinical hypothyroidism; TSH, thyroid-stimulating hormone; hs-CRP, high-sensitivity C-reactive protein; AI, atherogenic index; FMD, flow-mediated dilation; TC, total cholesterol; TG, triglycerides.

group independent of the classical risk factors for atherosclerosis. There is a seeming discrepancy between the results of the present study and previous studies regarding subclinical atherosclerosis in children with $\mathrm{SH}$. The possible explanations for these findings are: First, CA-IMT is measure of structural changes, whereas FMD is a dynamic measure that reflects the impact of both acute and chronic influences on endothelial function [38]. Since it is not possible to detect the disease duration and this may be directly related to the accumulated structural changes in the arterial wall, one can speculate that impaired FMD is preceding changes in CA-IMT in these patients with relatively short disease duration and the results that were seen in this study may simply represent an earlier stage prior to any change in CA-IMT [39]. Being able to identify the early changes in vascular function is important as endothelial dysfunction has been shown to be independently associated with the progression of CA-IMT over time [40].

In this study, we reported significant negative correlation between EFT and FMD that reminded significant after regression analysis, indicating that EFT is one of the predictors of and risk factors for subclinical atherosclerosis. Epicardial fat might contribute to atherosclerosis by secretion of adipocytokines that amplify vascular inflammation through paracrine effects, leading to local athero- 
genesis, plaque instability, and neovascularization [41]. Moreover, EFT has its intrinsic compressibility that play a permissive role in vessel expansion that leads to an asymmetric expansion of the vessel wall being defined as positive vessel remodeling [42].

In this study, the circulating levels of hs-CRP were significantly higher in the children with SH than in the control children. These findings are consistent with those of previous studies $[43,44]$, which demonstrated increased systemic inflammation in adult patients with $\mathrm{SH}$. Moreover, hs-CRP correlated positively and significantly with EFT that remain significant after regression analysis. It has been reported that $\mathrm{SH}$ results in low-grade chronic inflammation, which causes endothelial dysfunction, a promoter of atherosclerosis [32]. It is worth noting that endothelial dysfunction in $\mathrm{SH}$ could be related to lowgrade inflammation [44].

Treatment of $\mathrm{SH}$ is frequently initiated in many pediatric centers for persisting TSH elevations $>10 \mu \mathrm{IU} / \mathrm{mL}$, particularly in children with underlying HT and progressive deterioration of thyroid status over time [1]. Currently, there is a lack of recommendations for treatment of children with mild TSH elevations $(4-10 \mu \mathrm{IU} / \mathrm{mL})$. The present study may give a clue to researchers to move the limits of initiation of treatment of children with $\mathrm{SH}$ with mild TSH elevations.

To summarize, we have illustrated the presence of subclinical atherosclerosis in children with mild SH. This imposes a greater risk of early cardiovascular disease in such patients, which may be manifested in adulthood. We therefore believe in the necessity of early screening of these patients to prevent premature atherosclerosis. Our preliminary findings should be supported by further studies.

\section{Limitation of the Study}

The limitations of our study are: (a) The cross-sectional nature of the work. (b) Small sample size. (c) Absence of information on disease duration that might be influencing results. (d) The study included only children with SH due to AIT. (e) Only single operator performed echocardiography and noninvasive ultrasound for the studied cases.

\section{Conclusions}

Our study demonstrated higher EFT in children with SH compared with controls and correlated with FMD responses. Measurement of EFT by echocardiography in children with $\mathrm{SH}$ may help to identify those at high risk of developing subclinical atherosclerosis.

\section{Statement of Ethics}

The study protocol was approved by the Ethics Committee of Faculty of Medicine, Assiut Children's University Hospital, Assiut, Egypt. Written informed consents were obtained from the parents of all participants.

\section{Disclosure Statement}

All authors declared no potential conflicts of interest with respect to the research, authorship, and/or publication of this article. All authors approved the final manuscript as submitted and agree to be accountable for all aspects of the work. The authors have no financial relationships relevant to this article to disclose.

\section{Funding Sources}

No funding was secured for this study.

\section{Author Contributions}

H.S.F. participated in the design of the protocol of the study, coordination of the research, performance of the clinical part, performed the echocardiography, analyses of the data, and writing the draft of the paper. K.A.M. participated in the design of the protocol of the study, coordination of the research, performance of the clinical part, participated in the analyses of the data, and writing the draft of the paper. D.M.R. and M.A. participated in the design of the protocol of the study, coordination of the research, performance of the clinical part, performed the echocardiography. G.M.S. performed the laboratory investigations and participated in the analyses of the results. All the authors read and approved the manuscript.

References
Horm Res Paediatr 2019:92:99-105 DOI: $10.1159 / 000503287$
1 Crisafulli G, Aversa T, Zirilli G, Pajno GB, Corica D, De Luca F, et al. Subclinical hypothyroidism in children: when a replacement hormonal treatment might be advisable. Front Endocrinol (Lausanne). 2019 Feb;10:109.

2 Salerno M, Capalbo D, Cerbone M, De Luca F. Subclinical hypothyroidism in childhood current knowledge and open issues. Nat Rev Endocrinol. 2016 Dec;12(12):734-46.

3 Biondi B, Cooper DS. The clinical significance of subclinical thyroid dysfunction. Endocr Rev. 2008 Feb;29(1):76-131.

4 Crisafulli G, Gallizzi R, Aversa T, Salzano G, Valenzise M, Wasniewska M, et al. Thyroid function test evolution in children with Hashimoto's thyroiditis is closely conditioned by the biochemical picture at diagnosis. Ital J Pediatr. 2018 Feb;44(1):22.

5 Karmisholt J, Andersen S, Laurberg P. Variation in thyroid function in subclinical hypothyroidism: importance of clinical follow-up and therapy. Eur J Endocrinol. 2011 Mar; 164(3):317-23. 
6 Vanderpump MP, Tunbridge WM. Epidemiology and prevention of clinical and subclinical hypothyroidism. Thyroid. 2002 Oct; 12(10):839-47.

7 Radetti G, Gottardi E, Bona G, Corrias A, Salardi S, Loche S; Study Group for Thyroid Diseases of the Italian Society for Pediatric Endocrinology and Diabetes (SIEDP/ISPED). The natural history of euthyroid Hashimoto's thyroiditis in children. J Pediatr. 2006 Dec; 149(6):827-32.

8 Aversa T, Corrias A, Salerno M, Tessaris D, Di Mase R, Valenzise M, et al. Fiveyear prospective evaluation of thyroid function test evolution in children with Hashimoto's Thyroiditis presenting with either Euthyroidism or subclinical hypothyroidism. Thyroid. 2016 Oct; 26(10):1450-6.

9 Kahaly GJ, Dillmann WH. Thyroid hormone action in the heart. Endocr Rev. 2005 Aug; 26(5):704-28.

10 Biondi B, Fazio S, Palmieri EA, Carella C, Panza N, Cittadini A, et al. Left ventricular diastolic dysfunction in patients with subclinical hypothyroidism. J Clin Endocrinol Metab. 1999 Jun;84(6):2064-7.

11 Kilic ID, Tanriverdi H, Fenkci S, Akin F, Uslu S, Kaftan A. Noninvasive indicators of atherosclerosis in subclinical hypothyroidism. Indian J Endocrinol Metab. 2013 Mar; 17(2): 271-5.

12 Cerbone M, Capalbo D, Wasniewska M, Alfano S, Mattace Raso G, Oliviero U, et al. Effects of L-thyroxine treatment on early markers of atherosclerotic disease in children with subclinical hypothyroidism. Eur J Endocrinol. 2016 Jul;175(1):11-9.

13 Isik-Balci Y, Agladioglu S, Agladioglu K, Kilic-Toprak E, Kilic-Erkek O, Ozhan B, et al. Impaired hemorheological parameters and increased carotid intima-media thickness in children with subclinical hypothyroidism. Horm Res Paediatr. 2016;85(4):250-6.

14 Iacobellis G, Assael F, Ribaudo MC, Zappaterreno A, Alessi G, Di Mario U, et al. Epicardial fat from echocardiography: a new method for visceral adipose tissue prediction. Obes Res. 2003 Feb;11(2):304-10.

15 Bachar GN, Dicker D, Kornowski R, Atar E. Epicardial adipose tissue as a predictor of coronary artery disease in asymptomatic subjects. Am J Cardiol. 2012 Aug;110(4): 534-8.

16 Korkmaz L, Sahin S, Akyuz AR, Ziyrek M, Anaforoglu I, Kose M, et al. Epicardial adipose tissue increased in patients with newly diagnosed subclinical hypothyroidism. Med Princ Pract. 2013;22(1):42-6.

17 Balta S, Demırkol S, Kucuk U, Arslan Z, Unlu M, Yesil FG. Epicardial adipose tissue should be evaluated with other inflammatory markers in patients with subclinical hypothyroidism. Med Princ Pract. 2013;22(6):603-4.

18 Cooper DS, Biondi B. Subclinical thyroid disease. Lancet. 2012 Mar;379(9821):1142-54.

19 Surks MI, Ortiz E, Daniels GH, Sawin CT, Col NF, Cobin RH, et al. Subclinical thyroid dis- ease: scientific review and guidelines for diagnosis and management. JAMA. 2004 Jan; 291(2):228-38.

20 Radetti G, Maselli M, Buzi F, Corrias A, Mussa A, Cambiaso P, et al. The natural history of the normal/mild elevated TSH serum levels in children and adolescents with Hashimoto's thyroiditis and isolated hyperthyrotropinaemia: a 3-year follow-up. Clin Endocrinol (Oxf). 2012 Mar;76(3):394-8.

21 Diabetes Endocrine Metabolism Pediatric Unit, Cairo University Children's Hospital. Egyptian growth curves 2002. [http://dempuegypt.blogspot.com].

22 Tanner JM. Growth at adolescence. Oxford: Blackwell Scientific Publications; 1962. [cited Apr 10, 2018], http://www.epi.umn.edu/let/ pubs/img/adol_ch1.pdf

23 National High Blood Pressure Education Program Working Group on High Blood Pressure in Children and Adolescents (2004) The fourth report on the diagnosis, evaluation, and treatment of high blood pressure in children and adolescents. Pediatrics 114(2 Suppl 4th report):555-576.

24 Blumenthal S, Epps RP, Heavenrich R, Lauer RM, Lieberman E, Mirkin B, et al. Report of the task force on blood pressure control in children. Pediatrics. 1977 May;59(2 Suppl):III, 797-820.

25 Castelli WP. Lipids, risk factors and ischaemic heart disease. Atherosclerosis. 1996 Jul;124 Suppl:S1-9.

26 Matthews DR, Hosker JP, Rudenski AS, Naylor BA, Treacher DF, Turner RC. Homeostasis model assessment: insulin resistance and beta-cell function from fasting plasma glucose and insulin concentrations in man. Diabetologia. $1985 \mathrm{Jul} ; 28(7): 412-9$.

27 Iacobellis G, Assael F, Ribaudo MC, Zappaterreno A, Alessi G, Di Mario U, et al. Epicardial fat from echocardiography: a new method for visceral adipose tissue prediction. Obes Res. 2003 Feb;11(2):304-10.

28 Coretti MC, Anderson TJ, Benjamin EJ, Celermajer D, Charbonneau F, Creager MA, et al. Guidelines for the ultrasound assessment of endothelial-dependent flow-mediated vasodilatation of the brachial artery: A report of the international brachial artery reactivity task force. J Am Coll Cardiol. 2002 Jan;39(2): 257-65.

29 Järvisalo MJ, Jartti L, Näntö-Salonen K, Irjala K, Rönnemaa T, Hartiala JJ, et al. Increased aortic intima-media thickness: a marker of preclinical atherosclerosis in high-risk children. Circulation. 2001 Dec; 104(24):2943-7.

30 Kluger CZ, Morrison JA, Daniels SR. Preventive practices for adult cardiovascular disease in children. J Fam Pract. 1991 Jul;33(1):6572.

31 Aydogdu A, Karakas EY, Erkus E, Altıparmak İH, Savık E, Ulas T, et al. Epicardial fat thickness and oxidative stress parameters in patients with subclinical hypothyroidism. Arch Med Sci. 2017 Mar;13(2):383-9.
32 Belen E, Değirmencioğlu A, Zencirci E, Tipi FF, Altun Ö, Karakuş G, et al. The Association between Subclinical Hypothyroidism and Epicardial Adipose Tissue Thickness. Korean Circ J. 2015 May;45(3):210-5.

33 Lu S, Guan Q, Liu Y, Wang H, Xu W, Li X, et al. Role of extrathyroidal TSHR expression in adipocyte differentiation and its association with obesity. Lipids Health Dis. 2012 Jan;11(1):17.

34 Korkmaz L, Sahin S, Akyuz AR, Ziyrek M, Anaforoglu I, Kose M, et al. Epicardial adipose tissue increased in patients with newly diagnosed subclinical hypothyroidism. Med Princ Pract. 2013;22(1):42-6.

35 Castelli WP. Lipids, risk factors and ischaemic heart disease. Atherosclerosis. 1996 Jul;124 Suppl:S1-9.

36 Cerbone M, Capalbo D, Wasniewska M, Alfano S, Mattace Raso G, Oliviero U, et al. Effects of L-thyroxine treatment on early markers of atherosclerotic disease in children with subclinical hypothyroidism. Eur J Endocrinol. 2016 Jul;175(1):11-9.

37 Isik-Balci Y, Agladioglu S, Agladioglu K, Kilic-Toprak E, Kilic-Erkek O, Ozhan B, et al. Impaired hemorheological parameters and increased carotid intima-media thickness in children with subclinical hypothyroidism. Horm Res Paediatr. 2016;85(4):250-6.

38 Halcox JP, Donald AE, Ellins E, Witte DR, Shipley MJ, Brunner EJ, et al. Endothelial function predicts progression of carotid intima-media thickness. Circulation. 2009 Feb; 119(7):1005-12.

39 Tacito LH, Pires AC, Yugar-Toledo JC. Impaired flow-mediated dilation response and carotid intima-media thickness in patients with type 1 diabetes mellitus with a mean disease duration of 4.1 years. Arch Endocrinol Metab. 2017 Dec;61(6):542-9.

40 Hafner F, Kieninger A, Meinitzer A, Gary T, Froehlich H, Haas E, et al. Endothelial dysfunction and brachial intima-media thickness: long term cardiovascular risk with claudication related to peripheral arterial disease: a prospective analysis. PLoS One. 2014 Apr;9(4):e93357.

41 Sengül C, Özveren O. Epicardial adipose tissue: a review of physiology, pathophysiology, and clinical applications. Anadolu Kardiyol Derg. 2013 May;13(3):261-5.

42 Nakanishi R, Rajani R, Cheng VY, Gransar H, Nakazato R, Shmilovich H, et al. Increase in epicardial fat volume is associated with greater coronary artery calcification progression in subjects at intermediate risk by coronary calcium score: a serial study using non-contrast cardiac CT. Atherosclerosis. 2011 Oct;218(2):363-8.

43 Ridker PM. High-sensitivity C-reactive protein: potential adjunct for global risk assessment in the primary prevention of cardiovascular disease. Circulation. 2001 Apr;103(13):1813-8.

44 Taddei S, Caraccio N, Virdis A, Dardano A, Versari D, Ghiadoni L, et al. Low-grade systemic inflammation causes endothelial dysfunction in patients with Hashimoto's thyroiditis. J Clin Endocrinol Metab. 2006 Dec; 91(12):5076-82. 